\title{
On the Distribution of Radioactivity in the Sea around Bikini Atoll in June, 1954.
}

\author{
by
}

\author{
Y. Miyake, Y. Sugiura and K. Kameda \\ Meteorological Research Institute
}

(Received January 10, 1955)

\begin{abstract}
By the radioactivity in the air and sea water caused by the US hydrogen bomb tests in the area of Bikini-Eniwetok Atolls, 1954. The radioactivity contamination to fishes and fishing boats, were brought about. The observation of the actual state of the radioactivity around Bikini-Eniwetok Atolls was carried out aboard the survey boat "Shun. kotsu-maru". The maximum radioactivity in sea water was $7025 \mathrm{cpm} / l$ at $570 \mathrm{~km}$ west of Bikini and the influence of the radioactivity was recognized as far as about $2000 \mathrm{~km}$ from Bikini Atoll. Some oceanographic discussions on the horizontal as well as vertical distributions of the radioactivity in the sea are given.
\end{abstract}

\section{Introduction}

Leaving Tokyo Harbour on 15 th May, 1954, the observation were carried out until 4 th JuIy aboard the survey boat the "Shunkotsu-maru" belonging to the Ministry of Agriculture and Forestry in the sea area near Bikini Atoll where Hbomb tests had been done by U.S. Atomic Energy Commission, to make clear the state of the radioactive contamination to living matter, sea water, the air etc. The purpose of this "Japanese Bikini Expedition" was to obtain a counter-plan against the serious damage fell on the Japanese pelagic fisheries due to the radioactivity carelessly scattered in this sea area since the unfortunate affair of the fishing boat the "Fuku-ryu-maru", the "Lucky Dragon" on 1 st March, 1954.

In this expedition the present authors took charge of making a plan and ob. servations on the radioactive contamination of sea water and the air. Two of the authors (SUgrura and KAMEDA) participated in the expedition as observers. The fairly strong radioactivity was detected in wide area around Bikini Atoll, though U.S. Atmic Energy Commission had daclared that the presence of the radioactivity in the area was negligible [1]. In this paper the authors intend to report the results of observations and some oceanographic discussions regarding the distributions of the radioactivity near Bikini Atoll.

\section{The method of measurement of radioactivity in sea water}

It is dificult to measure the radioactivity in sea water directly by simple evaporation method owing to its high salinity, therefore, the carrier method has been adopted. After adding $2 \mathrm{gr}$ of solid ammonium chloride, $1 \mathrm{ml}$ of the aqueous solution of iron alum $(86.3 \mathrm{gr} / l)$ and $1 \mathrm{~m} l$ of barium chloride solution $(17.8 \mathrm{gr} / l)$ to 1 litre of sea water, water is heated to $60 \sim 70^{\circ} \mathrm{C}$ stirring well. A few drops of an alcoholic solution of phenol-phthalein (1\%) are added as an indicator, then ammonium 
hydroxide solution $(1 ; 1)$ is carefully dropped in with a pipet until a faint pink colour appears. After two minutes boiling, the precipitate is settled on standing for a couple of hours at room temperature. The precipitate is filtered under suction on a round filter paper (dia. $3.5 \mathrm{~cm}$ ) laying above the glass filter (Fig. 1). The precipitate remained on a filter paper is dried in an air bath or a desiccator holding in a small brass case (Fig. 2) to avoid the folding of the surface. Measurements of radioactivity are done by putting the precipitate kept in a brass case under a mica window of G-M counter. The G-M counter used aboard the "Shunkototsu-maru" is Radiation Counter, Model 32 manufactured by Science Research Institute Ltd., Tokyo. The thickness of mica window is $3.7 \mathrm{mg} / \mathrm{cm}^{2}$ and the distance between the mica window and the surface of the precipitate is $1.5 \mathrm{~cm}$. After the measurement has been done, the precipitate is covered by a polyethylene film to protect the surface. It was confirmed that at least $70 \sim 80 \%$ of the total activity in sea water could be transfered to the precipitate by preliminary tests using the fission materials fell aboard the fishing boat the "Fukuryu-maru". Therefore, the actual activities

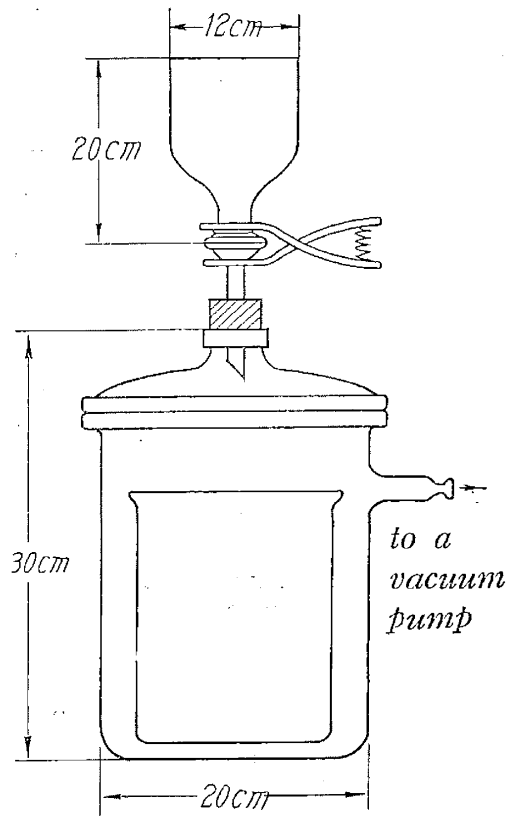

Fig. 1. The apparatus for filtration. might be $25 \sim 40 \%$ higher than observed values. To obtain the counting efficiency the aqueous solution containing Ce 144 of which activity had been referred to the

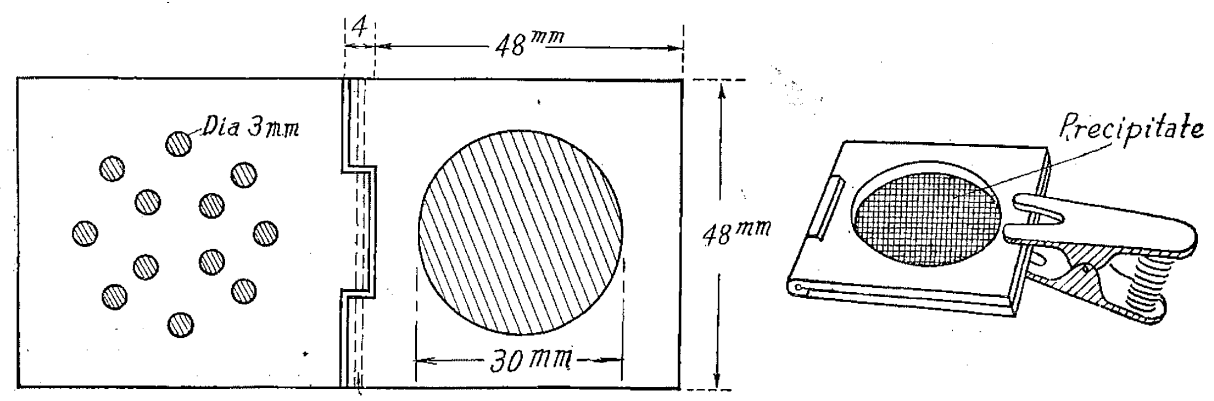

Fig. 2. A small brass case to avoid the folding of the surface of a filter paper.

standard RaE was treated chemically as mentioned above, and its radioactivity was measured under the same geometrical conditions. Thus, the efficiency of the measurement was found to be $7.7 \%$, that is, 1000 counts per minute is equivalent to about $5.9 \mathrm{~m} \mu \mathrm{C}$. The maximum activity in sea water obtained aboard by this method was $7025 \mathrm{cpm} / \mathrm{l}$ which was found at the depth of $75 \mathrm{~m}$, at $450 \mathrm{~km}$ west of Bikini Atoll on 21 st June.

The second was $6050 \mathrm{cpm} / \mathrm{l}$ found at the depth of $20 \mathrm{~m}$ at $150 \mathrm{~km}$ west of the atoll on 12 th June. It was confirmed that most parts of the radioactive materials were dispersed in water as true solutions, ionic or eucolloidal, since more than 
$99 \%$ of the radioactivity passed through a filter paper (pore size $0.5 \mu$, No, 4 Filter Paper, Tōyo Filter Paper Manufacturing Co., Tokyo).

It is rather surprising that the activity in sea water near Bikini and Eniwetok Atolls was often stronger than, or at least comparable to, that of White Oak Lake receiving waste effuent from nuclear reactors of Oak Ridge National Laboratory USA. The latter was $2710 \sim 5190 \mathrm{cpm}$ per litre on an average [2].

\section{The distribution of radioactivity in sea water around Bikini Atoll}

a) Horizontal distribution

Fig. 3 shows the horizontal distribution of the activity in the surface water near Bikini Atoll. There must have been some changes in the activity due to the time variation of the sea condition, the natural decay and the loss of the radioactivity during the course of observation. However, since the causes of changes were much complicated, and the correction were almost impossible, the distribution was drawn by using directly the observational data without giving any correction.

As shown in Fig. 3 the radioactive water extended on the WNW direction leav. ing near Bikini Atoll while a branch spread out to WSW. The cause of this branching is not clear. But, as explained below, it seems that there was a weak discontinuous boundary along the line passing Bikini and Eniwetok Atolls. The water $B_{1}$ (Fig. 4) on the northern side of this line had on an average the

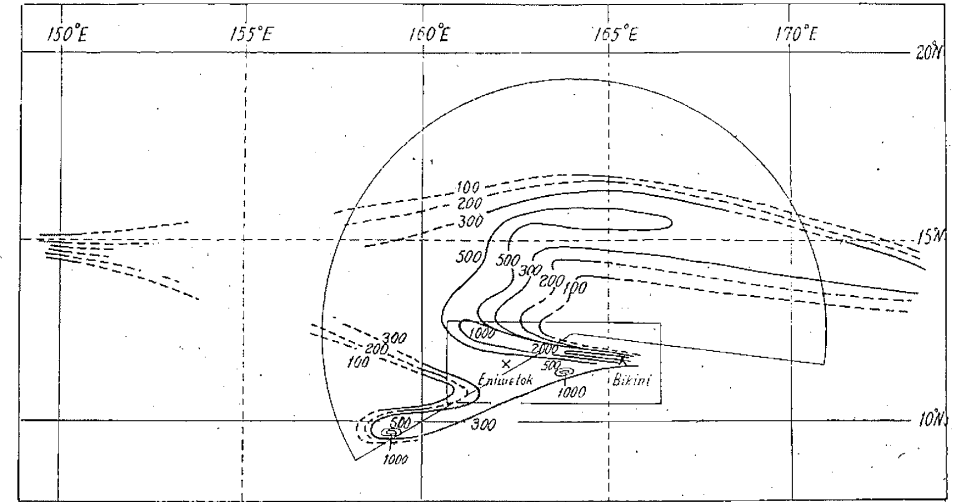

Fig. 3. The horizontal distribution of the radioactivity of the surface water. Number expresses the radioactivity in $\mathrm{cpm} / l$.

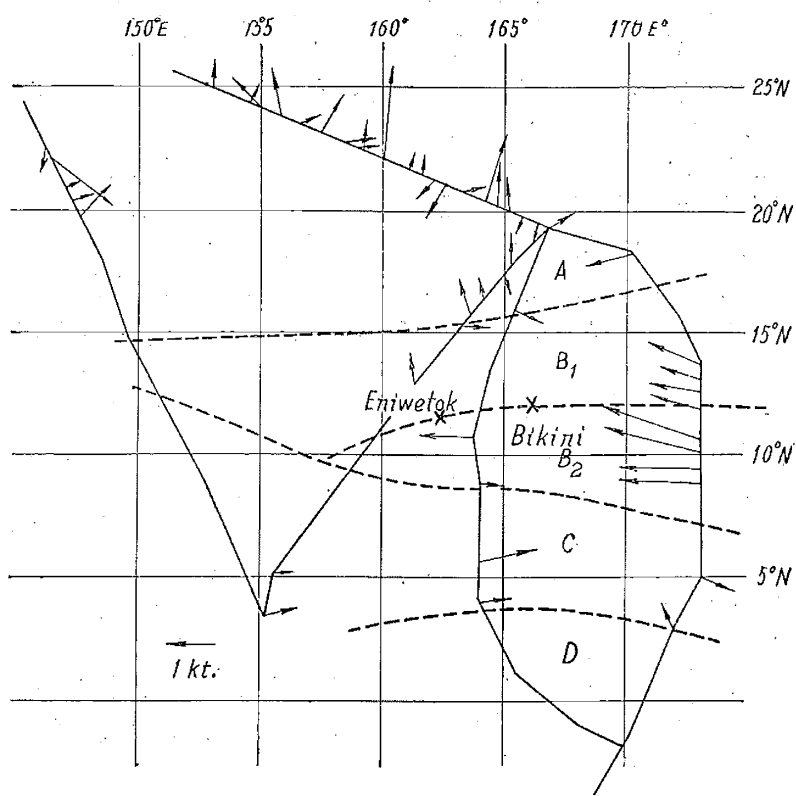

Fig. 4. The course lines of observation, the water systems, and the current speed and its direction. 
temperature, $27.1^{\circ} \mathrm{C}$, the chlorinity, $19.23 \%$ and $\sigma_{t}, 22.51$ at $50 \mathrm{~m}$ depth. On the other hand, the water system $B_{2}$ on the southern side of the line had $\mathrm{T}, 27.0^{\circ} \mathrm{C}$; $\mathrm{Cl}, 19.04 \%$ and $\sigma_{t}, 22.29$. Thus, it seems that there was a slight but definite jump in the properties between two water systems, which might be one of the causes of the branching.

The radioactive water flowing on the main direction of the North Equatorial Current extended sooner toward the west than in the southern part where the flow rate was smaller because the latter was near the boundary between the North Equatorial Current and the Equatorial Counter Current and there was also the oppression due to the north-eastward inclination of the Equatorial Counter Current. Thus, on the WNW direction the activity of $100 \mathrm{cpm} / l$ reached as far as $2000 \mathrm{~km}$ from Bikini Atoll, while on the WSW direction the extension was only $1000 \mathrm{~km}$.

It is to be noted that the radioactivity was also detected at the position $700 \sim$ $800 \mathrm{~km}$ from Bikini on the ENE direction. This is the end part of the radioactivity distribution turning to the east at about $350 \mathrm{~km}$ north of Bikini Atoll (Fig. 4). To clarify the cause of this turning on the backward direction of the North Equatorial Current may be one of the important problems.

Though it is not clear at present, whether it was the extention of the easterly current along the northern boundary of the North Equatorial Current which was found recently between $180^{\circ} \mathrm{E} \sim 140^{\circ} \mathrm{W}$ [3] or it was only the local eddy, several discussions will be done below on this point.

When we investigate the horizontal distribution of water systems near Bikini Atoll by using the T-S diagrams of waters at the depth of $50 \mathrm{~m}$ below the surface, we can find out that there are at least four different types of waters (Fig. 4). The first one $A$ is highly saline water (chlorinity, $19.3 \%$, water temperature, $27.5^{\circ} \mathrm{C}$, $\sigma_{t}, 22.77$ ) covering the area northern than $15^{\circ} \mathrm{N}$.

In the southern part of the atoll there is the second type of water $C$ which belongs to the Equatorial Counter Current with smaller chlorinity (C1, 18.9\%) and higher temperature $\left(\mathrm{T}, 28.0^{\circ} \mathrm{C}\right)$. The third one $B$ belongs to the North Equatorial Current representing the intermediate property between $A$ and $C$. In the southern part of the water $C$, there extends the water $D$ of the South Equatorial Current with higher chlorinity $(\mathrm{Cl}, 19.6 \%)$ and higher temperature $\left(\mathrm{T}, 28.0^{\circ} \mathrm{C}\right)$.

The water $B$ may be classified into two sub-groups $B_{1}$ and $B_{2}$ as mentioned above. As shown in Fig. 4 the east part of $B$ was comparatively broad and it became narrower on approaching to the west. It was probably due to that at the time the boundary between waters $B$ and $C$ somewhat inclined to the north. Therefore, the North Equatorial Current was pressed by the Equatorial Counter Current and the backward current flowing toward the north-east direction of Bikini Atoll would have been resulted.

The observation of the current direction obtained in situ also suggests the presence of counter or eddy current in the same area. It is, however, not sure whether this current would form the origin of the general easterly current as mentioned above.

On the other hand, a remarkable loop of the isochlor lines shown in the surface distribution of the chlorinity (Fig. 5) in the northern area of Bikini also indicates the presence of eddy flow.

As shown in Figs. 6 and 7 , in the vertical distributions of phosphate and the dissolved oxygen along $15^{\circ} \mathrm{N}$ there was the subsidence in the area near $15^{\circ} \mathrm{N}$, 
$165^{\circ} \mathrm{E}$ which was probably due to the anticyclonic eddy.

b) Vertical distributions of the radioactivity in sea water

Figs. 8, 9 and 10 show the distributions of radioactivity of sea water on the vertical section perpendicular to the North Equatorial Current along the lines respectively at $150 \mathrm{~km}, 570 \mathrm{~km}$ and $1300 \mathrm{~km}$ west of Bikini Atoll. The profile at $150 \mathrm{~km}$ west of Bikini shows already the branching of the activity in the direction of N-S. The dotted lines in the figures represent respectively the latitude of the sites of Bikini and Eni. wetok Atolls. The strong activity is separated on both sides of these dotted lines and the distance of two maxima is about 100 $\mathrm{km}$. The depth which shows the activity of 100 $\mathrm{cpm} / \mathrm{l}$ is at about $80 \mathrm{~m}$ below the surface in the northern and southern parts and in the middle part it sinks down to about $120 \mathrm{~m}$. It is noteworthy that the activity decreases rapidly down to only $28 \mathrm{cpm} / \mathrm{l}$ at $200 \mathrm{~m}$ depth. This corresponds to the depth of thermo-

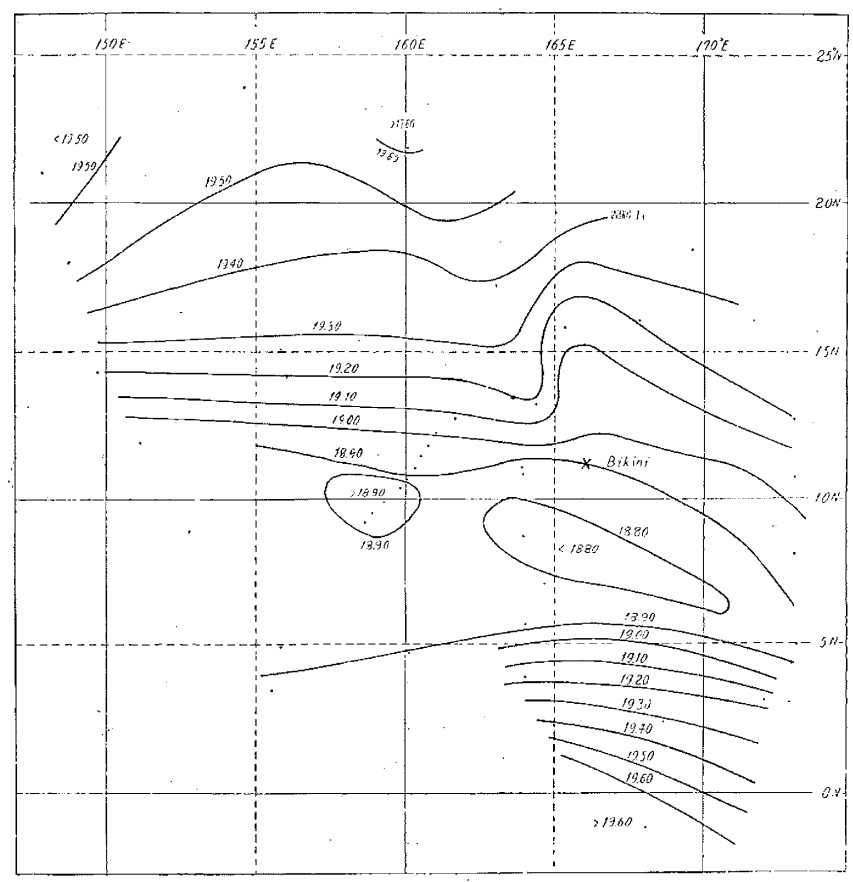

Fig. 5. The surface distribution of the chlorinity in \%.

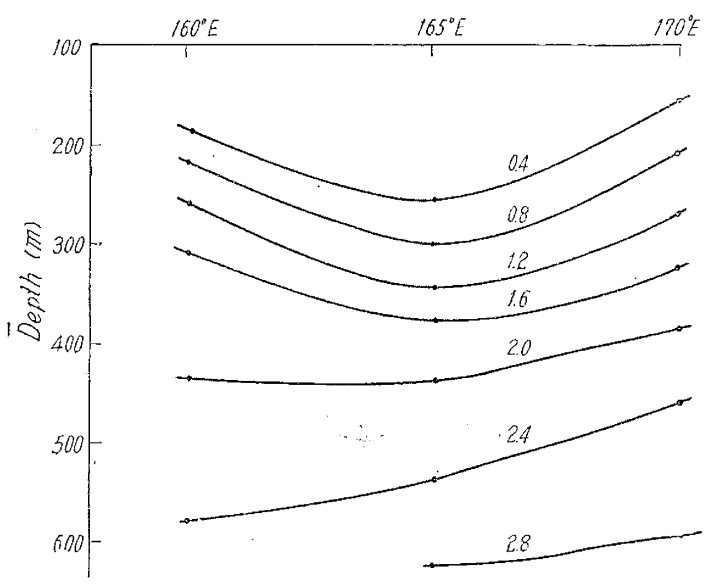

Fig. 6. The vertical distribution of the saturation rate of the dissolved oxygen $(\%)$ along $15^{\circ} \mathrm{N}$. cline which was about $150 \mathrm{~m}$ in this area.

The estimated amount of flow of radioactivity was about $1 \times 10^{5}$ curie/hour passing through this section. On the vertical section at $570 \mathrm{~km}$ west of Bikini the distance of branching became broader and also the depth of $100 \mathrm{cpm} / l$ activity was $200 \mathrm{~m}$ below the sea surface on an average. The flow of radioactivity was about $0.6 \times 10^{5}$ curie/hour. The distance between the former and the latter section was about $400 \mathrm{~km}$ and assuming that the speed of current was about $0.7 \mathrm{knots}$ 


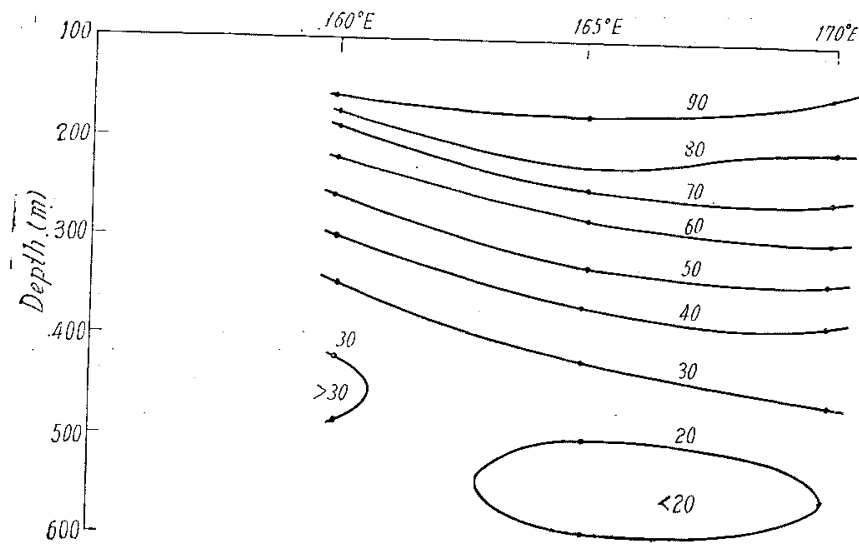

Fig. 7. The vertical distribution of phosphate $\mathrm{P}$ in $\mu \mathrm{g}$ atoms $/ l$.

Fig. 8. The vertical distribution of the radioactivity in sea water in the section perpendicular to the North Equatorial Current along the line at $150 \mathrm{~km}$ west of Bikini Atoll.
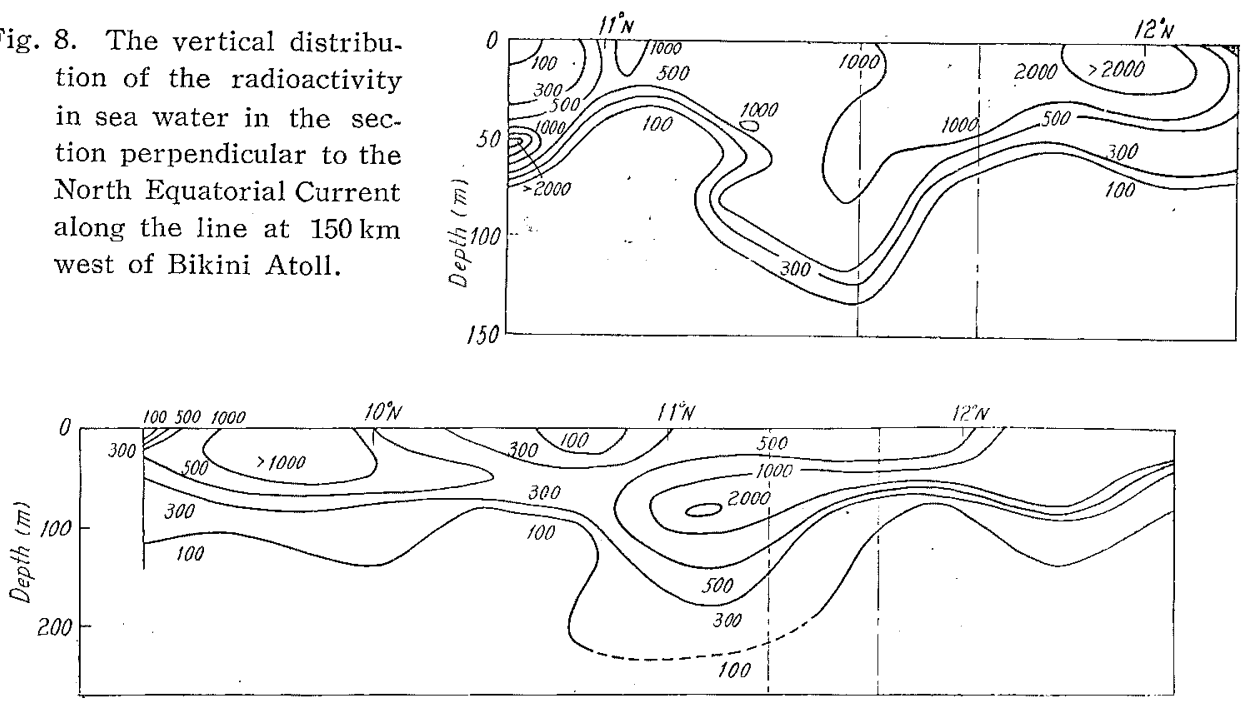

Fig. 9. The vertical distribution of the radioactivity in sea water in the section perpendicular to the North Equatorial Current along the line at $570 \mathrm{~km}$ west of Bikini Atoll.

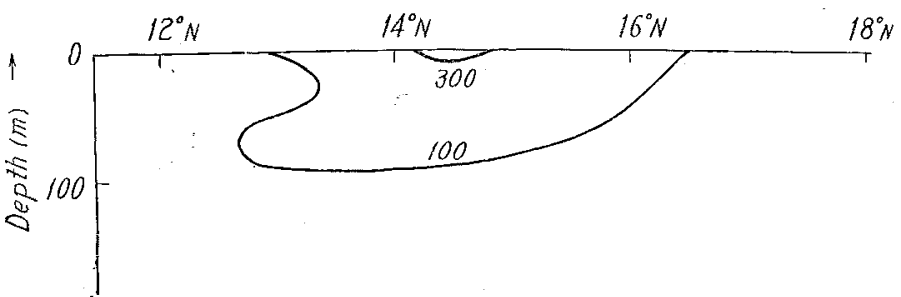

Fig. 10. The vertical distribution of the radioactivity of sea water in the section perpendicular to the North Equatorial Current along the line at $1300 \mathrm{~km}$ west of Bikini Atoll. 
on the direction perpendicular to the sections it would have taken about 2 weeks to flow between them. Thus, the activity passing through both sections would have been about the same when the rate of decay during two weeks was taken into consideration.

\section{The relation between the radioactivity in sea water and the radioactive fallout}

The fishing boat the "Fuku-ryu-maru" was situated at the position $150 \mathrm{~km}$ east of Bikini Atoll in the early morning on 1st March when her crews recognized small, white dust particles falling on the deck. The density of dusts covered the surface of the deck was not clearly known, however, it may be supposed that it was about $0.5 \mathrm{gr} / \mathrm{m}^{2}$ or so. On the other hand, the radioactivity of the dust particles was regarded as about 1.4 curie/gr at the time of falling ( 3 hours after the detonation) [4]. Assuming that the mean diameter of dust particles was 0.1 $\mathrm{mm}$, the rate of sinking of such particles in sea water is about $30 \mathrm{~m} / \mathrm{hour}$. Then, it takes about $1 \sim 1.5 \mathrm{sec}$ to pass the water layer of $1 \mathrm{~cm}$. Here, if we assume that at most $0.01 \%$ of the radioactive substances in the dusts could dissolve into sea water in one second, most part of radioactive materials. would have remove to water from dusts before they reached $100 \mathrm{~m}$ depth below the sea surface. Thus, the mean activity in water near the sea surface around there would have been $3.1 \times 10^{-6}$ curiell at the time five or six hours after detonation. Needless to say, this was the activity of sea water in the area about $150 \mathrm{~km}$ apart from Bikini Atoll, therefore, the activity near and in the atoll would have been much more stronger. On the other hand, it was confirmed by the records of micro-barographs and tide gauges obtained in Japan [5] that the detonations had been carried out four or five times since 1st March (1st March, 27 th March, 6th Apr.?, 26 th Apr. and 5 th May), it would be no wonder the wide sea area far from Bikini Atoll had been contaminated by fission materials as strongly as it was actually observed aboard the "Shunkotsu-maru" in June, 1954.

\section{The property on the radioactive substances in sea water}

The relation between the gross radioactivity $A_{(t)}$ of the fission materials and the time after detonation may be simply expressed by the next equation,

$$
A_{(t)}=c t^{-a}
$$

where $c$ and $\alpha$ are constants. From the decay curve of the radioactivity of the precipitates prepared aboard the "Shunkotsu-maru", it has been found that $\alpha$ is confined within the comparatively narrow limits of $1.3 \sim 1.6$ (mean, 1.5) assuming the date of detonation was 5th May. In normal cases, $\alpha$ is about $1.2[6]$, whereas it was 1.37 for the radioactive dusts fell on the deck of the "Fuku-ryu-maru".

In sea water some of the radioactive elements contained in the original fission materials might be preferentially precipitated owing to $\mathrm{pH}$ of sea water, (about 8.2 8.3). Therefore, the chemical composition should be somewhat different from the original fission materials, which might be the cause of the change in the value of $\alpha$.

The radiochemical analysis of the fission materials in sea water have been furnished also by the present authors which will be reported in near future. In Table 1 the full data of the gross activity of sea water observed aboard the observation vessel are given. 
Acknowledgements — The authors wish to express their thanks to Dr. H. YaBe, the leader of the Expedition, Messrs. G. Yoshm, H. Miyóshr, Y. YazAki who carried out the radioactivity measurement aboard the ship, and also to members of laboratories of Dr. K. Kimura and Dr. E. Minami at Tokyo University for their help and cooperation.

\section{References}

[1] US Atomic Energy Commission, 1950: Radiobiological Survey of Bikini, Eniwetok and Likiep Atolls, July-August, 1949. AECD-3446.

[2] Radioisotope Uptake by Aquatic Plants and Animals Living in Waste Effluents of Oak Ridge National Laboratory; A paper presented to U.S.-Japan Radiobiological Conference held in Tokyo, 1954.

[3] Cromweld, T., 1953: Circulation in a Meridional Plane in the Central Equatorial Pacific. Jour. Mar. Res., 12, p. 196.

Barnes, C.A., Bumpus, D F, and Lyman, J., 1948: Ocean Circulation in Marshall Island Area. Trans. Amer. Geophys. Union, $29(6)$.

[4] Krmura, K. et al., 1954: On the Radioactive Substances Having Precipitated on the Fishing Boat the "Fuku-ryu-maru". Japan Analyst, 3, p. 335. (in Japanese).

[5] Yamamoto, R., 1954: The Microbarographic Oscillations Produced by the Explosions of Hydrogen-Bombs. Bull. Inst. Chem. Res. Kyoto Univ. The Radioactive Dust from the Nuclear Detonation.

Central Meteorological Observatory, Tokyo, 1954: A Preliminary Report of Observations on the Atmospheric and Oceanic Oscillations caused by H-Bomb Tests. (in Japanese)

[6] Hun'er, H.F. and Ballou, N.E., 1951: Fission-Product Decay Rates. Nucleonics, 9 p. C-2. 
Table 1. Radioactivity in. sea water at various depths near Bikini-Eniwetok Atolls, 1954. $1000 \mathrm{cpm}$ is equivalent to about $5.9 \mathrm{~m} \mu \mathrm{C}$.

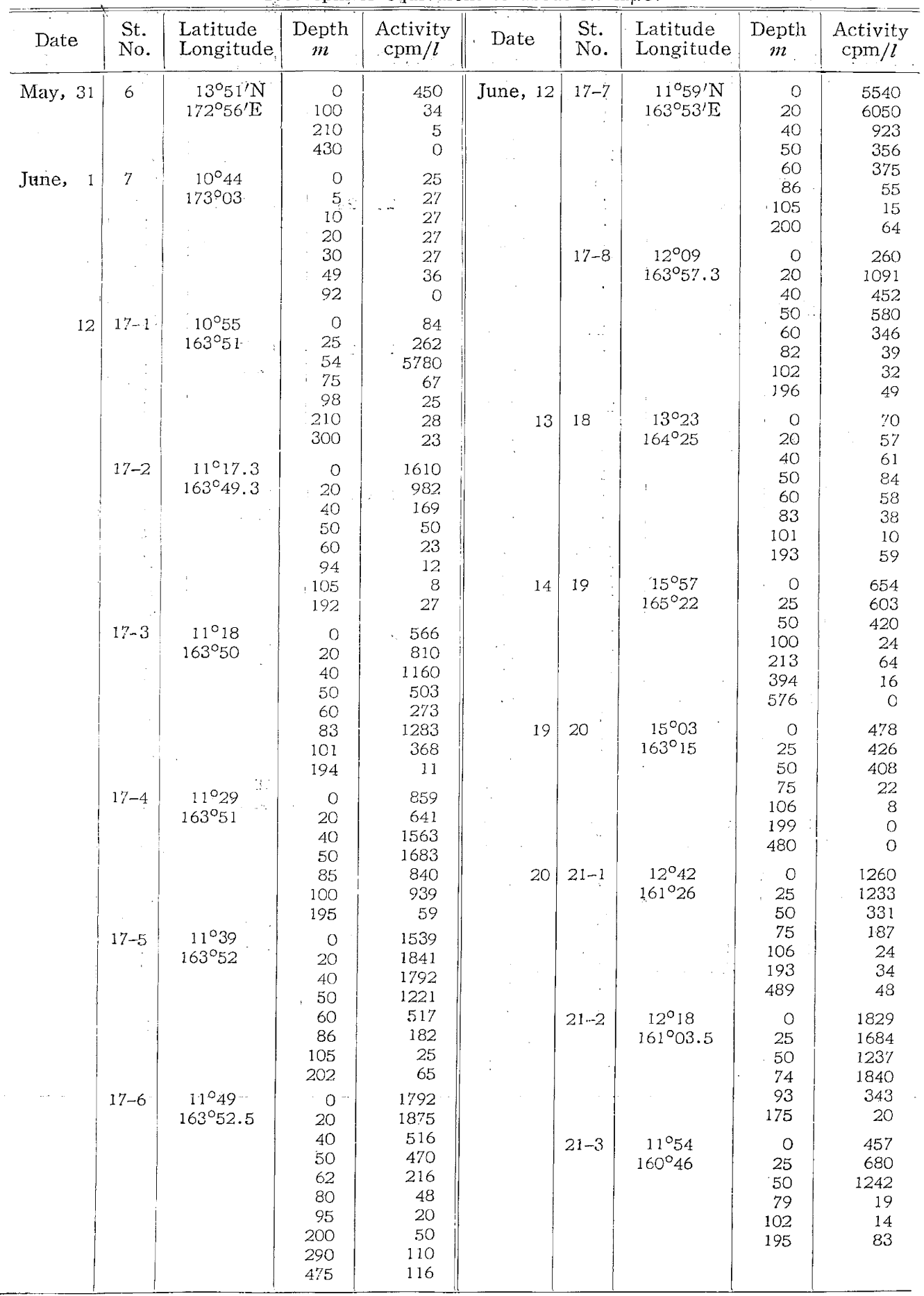




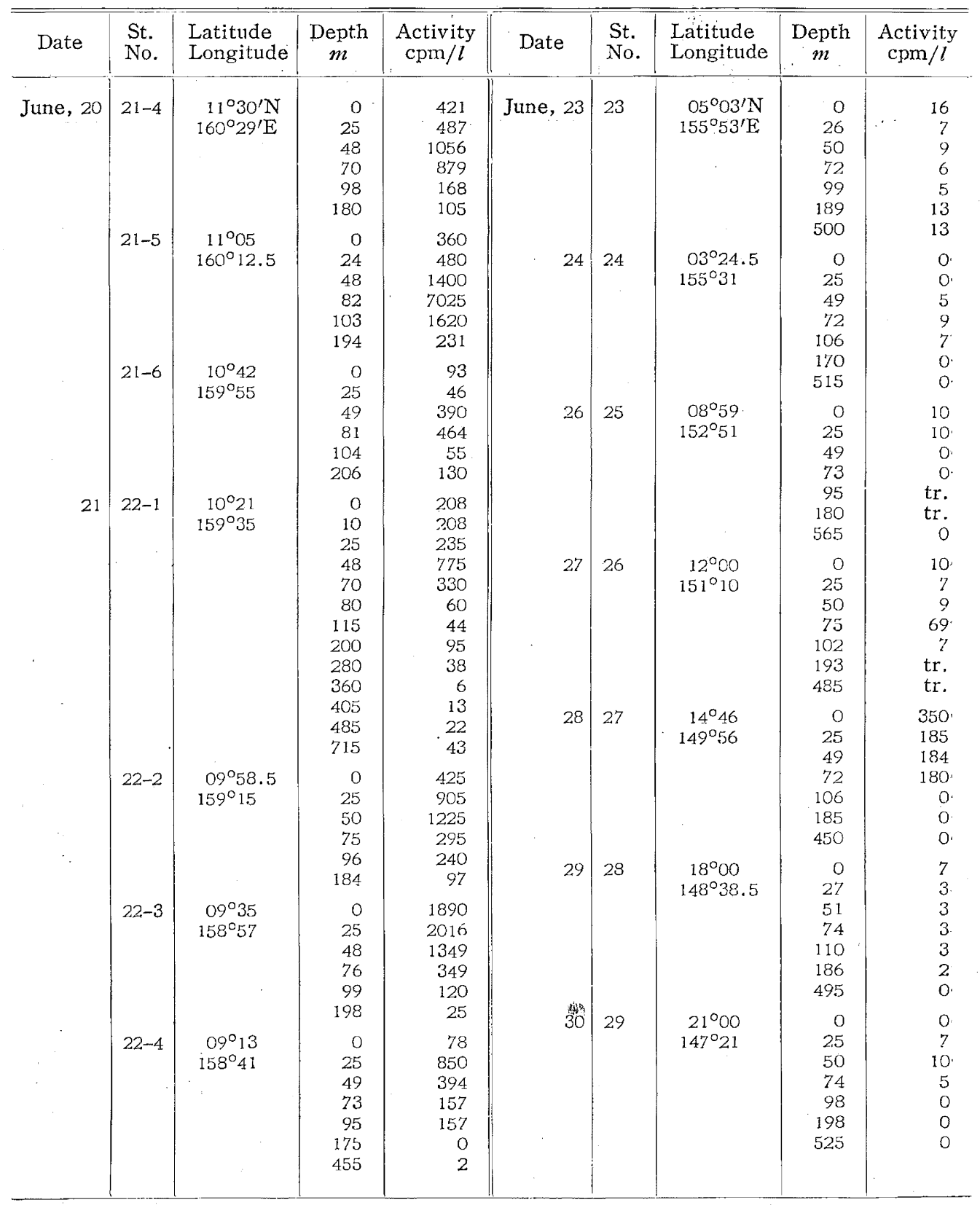

